Special Section

Am. J. Nephrol. 1984;4:315

\title{
Medical Art
}

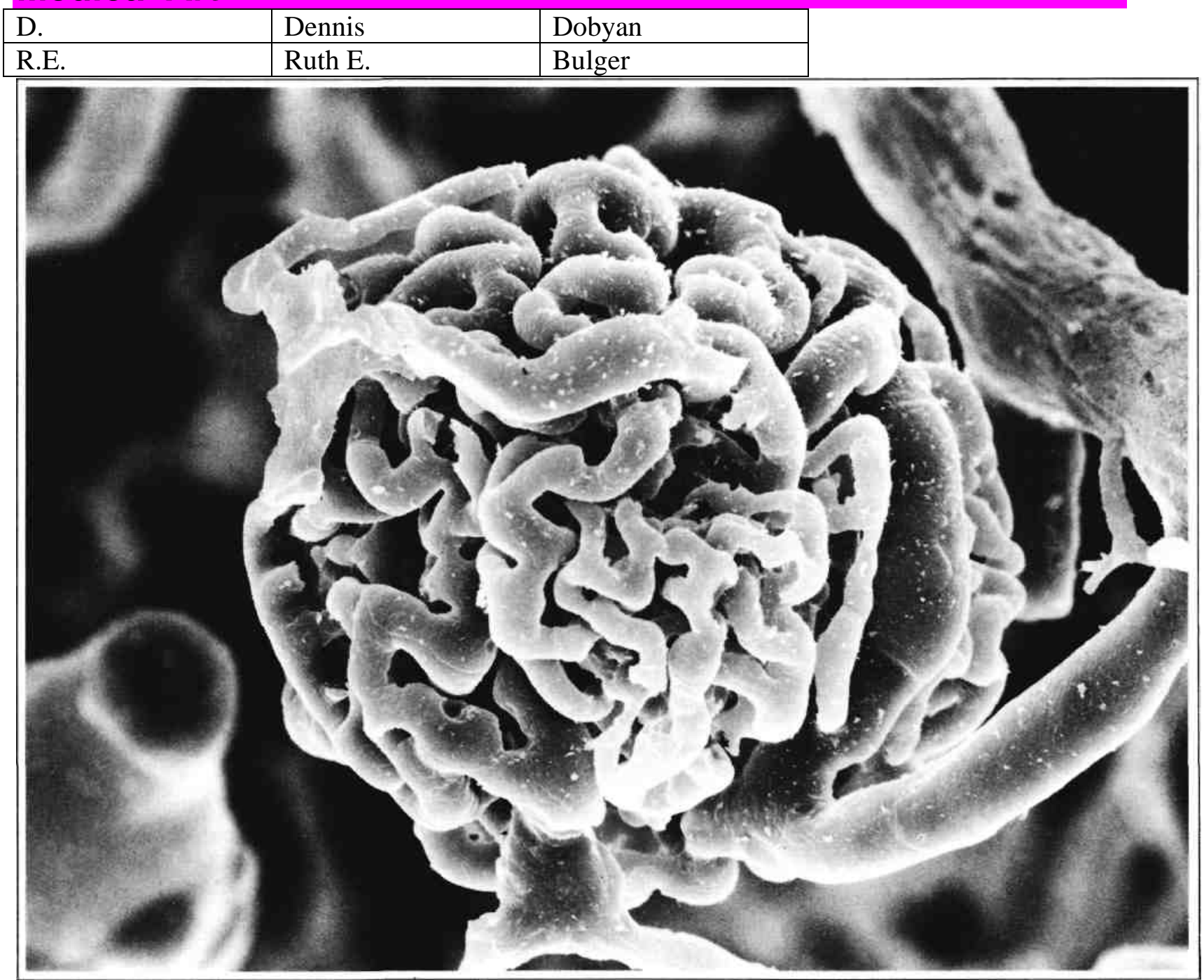

Plasticin cast of the glomerular capillary tuft from a rat kidney, demonstrating the afferent arteriole (on the lower right) originating from an interlobular vessel. The efferent can be seen at the bottom of the figure. $\times 1,050$. 